\title{
Mapping strategic groups in higher education: Evidence on the Polish technical faculties
}

\author{
Michał Pietrzak, Warsaw University of Life Sciences, Poland, michal_pietrzak@sggw.pl \\ Piotr Pietrzak, Warsaw University of Life Sciences, Poland, piotr pietrzak1@sgw.pl
}

\begin{abstract}
According to the New Public Management (NPM) concept, public agencies (in such number universities) have to strive for the efficiency analogous to the private counterparts by among others private sector styles of management practice ('proven' tools). One of the groups of the 'proven' and widely used tools are those connected with the strategic management. Could strategic management tools be helpful for management of public universities? The aims of this paper are twofold: to discuss the potential and usefulness of strategic groups map in the higher education and to test empirically differences of efficiency between mapped groups. This article presents map of strategic groups of faculties of engineering and technology sciences affiliated at public universities in Poland. The investigation was based on the convenient sample of 48 faculties, thus the study should be treated as pilot researches. Following Ward's method four strategic groups of faculties were delineated, namely: "Scientific Entrepreneur", "Authors", "Middlers" \&"Teachers". Each of these groups is characterized in this article. Then the differences in performance according to the groups' membership were tested. Based on the chisquare $\left(\chi^{2}\right)$ statistics we find differences in efficiency between strategic groups.
\end{abstract}

Keywords: strategic groups, higher education, efficiency, performance measurement,

\section{Introduction}

Education is seen as a pathway to the development of nations in the age of the knowledge based economy. Particularly, higher education is the key enabler of creating and upgrading human capital and knowledge (Porter, 1990). Supply of higher education creates positive externalities i.e. benefits to the economy that exceed those to any individual who consumes it (Begg, Fischer, \& Dornbusch, 2014; McMahon, 1982; Warning, 2004). Thus, close connections between higher education system and economic growth (Warning, 2004) explains why the delivery of teaching and academic research is often publicly supported. On the other hand, the governments and their public agents do not produce any good either the best or the most efficiently (Bowden \& Bowden, 2002). Taxpayers create a pressure on the public agencies to be more elastic and entrepreneurial organizations, namely environment servant organizations (Ansoff, 1979). This pressure led to the development of the New Public Management (NPM) concept. From the theoretical point of view NPM could be seen as the mix of the new institutional economics (the public choice theory, the transaction cost theory, the principal-agent theory) and business-type management theory (Hood, 1991). This hybrid offers the theoretical underpinnings of the critique of the traditional approach to the supply and management of public services based on Weber's model of ideal bureaucracy (O'Flynn, 2007). Thus, public agencies have to strive for 
the efficiency analogous to the private counterparts by: hands-on professional management, explicit standards and measures of performance, emphasis on output controls, disaggregation of units, competition, private sector styles of management practice ('proven' tools), discipline and parsimony in resource use (Hood, 1991). These ideas have been applied recently to the higher education institutions (Schimank, 2005; Tahar, 2013; Wilkesman \& Schmid, 2012).

Consequently, public institutions of higher education started to use methods and techniques developed for the business sector (Parker, 2012). One of the groups of the 'proven' and widely used tools are those connected with the strategic management. Even though we can observe the process of overlapping of the features of business firms and publicly held organizations there are, however, still important differences between companies and not profit-oriented agencies (Ansoff, 1979). Thus, one could doubt about compatibility of approaches and tools used in these both types of organizations. Could strategic management tools be helpful for management of public universities? Pietrzak (2014) as well as Pietrzak, Paliszkiewicz, and Klepacki (2015a) studied the case of implementation of one of such tools, namely Balanced Scorecard in the publicly held higher education institution and assessed usefulness of this method. Strategic groups map is another promising tool, which could be used in strategic knowledge acquisition (Pietrzak, Jałosiński, Paliszkiewicz, \& Brzozowski, 2015b). The aims of this paper are twofold. Firstly, we will discuss the potential and usefulness of strategic groups map as a tool of strategic management in the higher education. Secondly, this tool will be tested empirically on the sample of 48 technical faculties in Poland. Differences of efficiency between groups will be verified. Our paper is organized as follows. In the theoretical background we present the genesis and the essence of the strategic groups concept and discuss the possibility of using it public sector. We also present review of the research done in this area. In the material and method section we explain our methodological assumption, in particular, sampling, data set, statistical procedure used for clustering, method of performance assessment. We also conjecture the hypothesis to testify. In the results section we present our empirical findings according to clustering and performance measurement. Our paper is finished with the conclusions section.

\section{Theoretical background}

Strategic management is diversified theory. There are many schools of thought in this field. Mintzberg, Ahlstrand, and Lampel (1998) listed as many as ten of such schools. One of the most influential schools mentioned by Mintzberg et al. (1998) is the positioning school, which is firmly rooted in economics. Porter (1998a), the most prominent representative of positioning school, claims that the first key problem lying at the base of strategic choices regarding competitive strategy is the structure of the sector in which any firm operates: "competitive strategy is the search for a favorable competitive position in an industry, the fundamental arena in which competition occurs" (p. 1). This point of view is drawn from Industrial Organization (IO), a branch of economics. Fundamental for IO research agenda is the Structure-ConductPerformance paradigm, which implies that the structure of the industry determines the conduct of the firms within this industry (namely strategies). Conduct in turn influences performance of the industry defined in terms of efficiency (Carlton \& Perloff, 2005; Porter, 1981). Thus, the S-C-P model states that differences between the sectors' structure should explain most of the differences in profitability between sectors (McGahan \& Porter, 1997). That conjecture was 
tested in many empirical studies (in such number see: Schmalensee (1985), Rumelt (1991), McGahan and Porter (1997). The results are equivocal: "while industry differences matter, they are clearly not all that matters" (Schmalensee, 1985).

In fact, even though there are observable differences between industries, there are also crucial intra-industry differences in efficiency. One of the possible elucidations of these differences is the strategic groups existence. The concept of strategic groups was developed in collateral studies conducted by Caves and his students at Harvard Department of Economics and by Schendel and Cooper and their students at Purdue University (Rumelt et al., 1991). Initially, strategic groups were a construction build up on a basis of IO, however, it was adapted into the newly grown field of strategic management. Hunt, one of the Caves' students, was the first who coined the term "strategic groups" in 1972 to describe "a group of firms within the industry that are highly symmetric (...) with respect to cost structure, degree of product differentiation, degree of vertical integration, and the degree of product diversification (...) formal organization, control systems, management rewards and punishments (...) and the personal views and preferences for various possible outcomes" (cited by Fiegenbaum, McGee, \& Thomas, 1987, p. 8). The term strategic group was popularized by Porter, who proposed following definition: "the group of firms in an following the same or a similar strategy along the strategic dimensions" (Porter, 1998a). The different positions of strategic groups in any sector result in differences in efficiency of group members (McGee \& Thomas, 1986).

The strategic groups map is helpful in answering crucial questions such as: how is competition conducted, what are consequences of different types of strategic behaviors, what is the dynamic of competition within industry, and how do players change (Pruett \& Thomas, 1994). Traditionally to address those questions economists have looked at industry level of analysis (SC-P paradigm), while students of business policy have looked at individual organizations and even at a managers' level. As Thompson and Strickland (1990) stated that the strategic groups map is used to evaluate the competitive position of the sector members and is a kind of bridge between seeing a sector as a whole and looking at individual organizations as separate units (1990). The strategic grouping of organizations allows segmenting any sector into set of organizations that pursue similar strategies. Thus, it could be a powerful tool in the armory of strategic analyst (Hatten \& Hatten, 1987).

Strategic groups map has a great practical potential that allows one to identify groups with different perspectives for the future by taking a snapshot of where the firm is today and where their competitors are. The differences in strategies are strongly informative to predicting the changes that may occur in any sector due to the movement of individual companies or entire strategic groups. Such prediction could give the right knowledge for making the right decisions and action plans. Having mapped the present and predicted organization's competitive position against its rivals, one could plan future actions. In such a way, strategic groups map is a source of dynamic knowledge of the competitive environment and therefore could be treated as a strategic knowledge management tool (Pietrzak et al., 2015b).

There are many empirical investigations conducted about strategic groups in plenty business industries (for a review see for example: McGee \& Thomas, 1986), however, an interesting issue remains the question of using the strategic groups map in other fields of economic activity, namely second (or public) sector and third (or voluntary) sector. There are only a few studies 
done in this area. Domański (2010) made the first attempt to strategic grouping of nongovernmental organizations. His procedure based on cluster analysis yielded a set of five strategic groups of third sector organizations in the area of science, culture and education, namely: 'Foundations', 'National Associations', 'Friends of Societies', 'County Associations' and 'Provincial Associations'. Domański (2010) confirmed correlation between group membership and performance measured by revenue. There are little more studies conducted in the public sector in such number research for hospitals (Nath \& Gruca, 1997) and for higher education institutions (Adam, 2016; Martinez \& Wolverton, 2009; Warning, 2004, 2007; Wójcik-Augustyniak, 2011).

The last part of those studies is particularly interesting according to the topic of our paper. The higher education sector is becoming increasingly competitive (Warning, 2007). As "the concept of strategic groups has primary been applied to business (...). The strategic group concept can also be applied to the higher education industry" (Martinez \& Wolverton, 2009, p. 64). Warning (2007) made the first attempt at segmenting higher education sector into strategic groups on the example of public universities in Germany (2004). Warning (2004) assumed that universities make the trade-off between emphasis on teaching or on research activity. Grouping based on statistical methods was done according to universities preferences to invest in teaching or to invest in research. Warning (2007) showed that returns from investment in research are significant for high-ranked universities but are measly for low-ranked universities.

Typically studies of strategic groups are based on sophisticated statistical methods such as: cluster analysis, factor analysis, discriminant function and possibly others multidimensional statistical techniques. However, frequent drawback of those studies is lack of any visualization of such grouping, namely map of strategic groups. Possibility of aggregating multidimensional data sets about diversified organizations into user-friendly and easy to interpret two-dimensional picture is very important for practical usefulness of strategic groupings (see procedure for constructing a strategic group map given by: Thompson, Peteraf, Gamble, \& Strickland, 2012). As Pietrzak et al. (2015b) emphasized such visualization is a kind of smart simplification which is a fundamental issue for processing information into decisions and actions, therefore for knowledge acquiring. Those authors also argue that this visualization could be done basing on statistical clustering, particularly when map creator have not deep knowledge about industry and patterns of firms' strategic behavior. However, when one has deep knowledge about industry and firms within it, he or she could be justified to base on qualitative judgment in classification firms into strategic groups rather than on statistical procedures (Pietrzak et al., 2015b). Martinez and Wolverton (2009) follow this way in creating map of the global postsecondary education and training industry. However, the industry delineation they used could be questionable in two aspects. Firstly, one could claim that product market definition used by these authors is too broad, and secondly, geographical market delimitation seems to be also too broad.

Wójcik-Augustyniak (2011) is the first attempt to use strategic grouping for segmenting the higher education sector in Poland. Her approach is based on simple combinations of three-tier classifications framing on six criteria. Her approach is not convincing from two points of view. Firstly, the criteria used for grouping are drawn from one of the domestic ranking of HEIs conducted by private institution. Therefore the methodology of this ranking is not fully transparent. Secondly, the classification is conducted in the rather mechanical manner. Adam 
(2016) performed the latest research on strategic grouping of HEIs. She conducted several empirical analyses based on the content of mission statements of 521 US business schools (AACSB accredited). Adam (2016) used the method of qualitative content analysis to extract strategy from the mission statements. Based on them and conducting hierarchical cluster analysis she received classification of four strategic groups with similar strategies. However, the methodology used by her, which is based on the assumption that mission statements, contains expressions which represent strategic distinctiveness is controversial, indeed. One could doubt, that using differences in official statements instead of "hard" data about observable behaviors could easy lead to classification of groups, which are artifacts rather than real beings.

The studies of strategic groups in higher education sector are not numerous and results achieved are controversial thus, it seems justifiable to undertake investigation in this area. Moreover, we will use original approach, different than used by authors referred above, which treated the university as a basic analytical unit. However, typically higher education institutions consist of many different faculties (this is particularly striking in the big universities). In the business literature it is emphasized difference between strategy on the corporate level and strategy on the business unit level (De Witt \& Meyer, 2005). In fact any big corporation operates in many industries (sectors) simultaneously. Strategic groupings are done for any particular sector, therefore strategic groups map is the tool used for crafting strategy on the strategic business unit level. Analogously, we are convinced, that mapping of strategic groups should be done rather on faculty than on whole university level.

\section{Material and method}

As we mentioned above our basic assumption is, that the basic unit of both competition and strategic decisions should be the faculty instead of the university treated as a whole (which could be seen analogously to the corporate umbrella in business). Thus, we decided to choose the faculties of engineering and technology sciences (i.e. architecture, transport, electronics, mechatronics, civil engineering, production engineering) affiliated at public universities in Poland. There are about 120 such faculties in Poland. The data only from 48 of them were available to collect. Bonaccorsi (2014) emphasized, "there is an area, however, where microdata are surprisingly missing (...) there are actors that produce and diffuse knowledge that are invisible in official statistics - namely, universities" (p. 2). This is also true in the case of many Polish universities. Only a few universities (Warsaw University of Technology, Lublin University of Technology, Czestochowa University of Technology, Rzeszow University of Technology, Silesian University of Technology, Warsaw University of Life Sciences, University of Zielona Góra, University of Silesia in Katowice, University of Warmia and Mazury in Olsztyn, Poznan University of Life Sciences) published detailed reports that contain data indispensable for our research. In fact our set of faculties is convenient sample and is not randomized, therefore our research is not representative and should be treated as a pilot study. Nevertheless, our sample represents about $40 \%$ of the population.

In creating a strategic group map we followed the procedure given by Thompson et al. (2012, $\mathrm{p}$. 126): (1) identification of dimensions that differentiate firms within industry, (2) plotting firms on a two-dimensional map based on two dimensions from the list identified above, (3) assigning 
firms that fall in similar space on this map to the same strategic group, (4) drawing circles around each group.

In order to do construction of strategic groups maps properly it is important to define the criteria for differentiating business strategy for the sector. In this paper authors developed approach, which core is drawn from Warning (2004). Warning (2004) emphasized crucial trade-off between focus on teaching and focus on research. However, we made some modification in her approach. We observe that in HEI's in Poland focus on research means usually increasing activity on writing scientific papers. This is due to the assessment criteria used both on the individual researcher and on institutional level. These criteria are based on the number of publication and on citation indexes. However, in many cases such publication activity has no any leverage on practical aspects. Therefore, there is a little transfer of knowledge from science to practice observed. Thus, we decided to distinguish between 'theoretical' research activity (writing scientific papers) and 'practical' research activity (conducting research oriented on needs of university environment - measured by the value of externally acquired funds i.e. money from governmental or European Union grants based on competition and money from business). We still follow general idea of Warning (2004), that there is strategic trade-off between teaching and research. Thus, we define two dimensions that differentiate HEIs (faculties) within sector of engineering and technology sciences: the number of publications versus the number of students (to illustrate tension between teaching and 'theoretical' research) and the value of externally acquired funds versus the number of students (to illustrate tension between teaching and 'practical' or 'entrepreneurial' research activity). One should be aware that only quantitative measure (number of publications) was available for all faculties from the sample. Only a few faculties published reports with measures, which allows for qualitative assessment of publications.

On the basis of two dimensions described above we conducted cluster analysis based on Ward's method. This technique uses an analysis of variance approach. It attempts to minimize the Sum of Squares (SS) of any two (hypothetical) clusters that can be formed at each step. Ward's method is regarded as very efficient (Hair, Black, Babin, \& Anderson, 2009), however, it tends to create clusters of small size. Strategic groups are marked on the map by circles. Typically, the size of the circle indicates the importance of the particular group in the sector, usually measured by combined sales of their group's members (Thompson et al., 2012). Instead of sales we used number of student as a measure of the groups' size.

In theory of strategic groups it is assumed that differences in strategic dimensions are connected with different performance. We conjecture the following hypothesis: efficiency is related to differences between strategic groups (their profiles).To verify this conjecture we calculated efficiency ratio based on Data Envelopment Analysis (DEA) method. DEA is a non-parametric mathematical programming approach for measuring relative efficiencies of comparable Decision Making Units (DMUs) with respect to multiple inputs and outputs (for more details see e.g.: Charnes et al., 1978). We used one variable as an input (total number of academic staff) and three variables as outputs for calculating DEA efficiency score. Choosing outputs' variables we tried to take into account an evolution from liberal (Humboldtian) to entrepreneurial model of the university. In such a new model, the general mission of the university is enlarged and consists of three pillars not only research and teaching but also supporting the economic and social 
development. As first output we chose number of students (reflecting the activity in teaching). We are aware that number of graduates will be more precise but such variable was not available. As a second output we used number of publications (reflecting the activity in scientific work). As third output we chose value of externally acquired funds like funds for R+D work etc. (reflecting the activity in supporting the development of university's environment).

It is not common in public universities in Poland to fire academic staff except for immoral acts, the loss of mental competence etc. It means that reducing staff is not accepted objective in such institutions. Thus, we assumed that the output-oriented DEA model would be more appropriate than an input-oriented one. Because the number of studied units (faculties) was not high, we decided to use the CCR model (in the BCC model the number of efficient units is always higher than in the CCR model). In summary, this research study used the CCR output-oriented model.

To confirm our hypothesis we used chi-square $\left(\chi^{2}\right)$ statistics to verify following statistical test:

- $\mathrm{H}_{\mathrm{o}}$ : DEA efficiency score is not correlated with strategic groups' membership,

- $\mathrm{H}_{1}$ : DEA efficiency score is correlated with strategic groups' membership.

In calculations we used popular software packages like: STATISTICA 7.0, DEASolverPro and MS Excel 2013.

\section{Results}

The clustering procedure is given in figures 1-2 and table 1. Figure 1 illustrate amalgamation schedule. One could observe that at $45^{\text {th }}$ step Euclidean distance rise sharply at value 3.9 (indicated by red line). Determining 3,9 as a cutoff point (as suggested by the amalgamation schedule in Figure 1) results in four distinct clusters of faculties (Figure 2).

Table 1. reveals that the clusters contain the following numbers of faculties: cluster A - 1 faculty, cluster B - 4 faculties, cluster $\mathrm{C}-18$ faculties and cluster D -25 faculties. The total value of externally acquired funds per one student in cluster A is about 93 thous. PLN (1 USD is equivalent of about 4 PLN). This is about 13 times higher value than average for the sample (7 thous. PLN). Thus we called the Faculty of Materials Science and Engineering (FMSE(WUT)) the only one member of cluster A - as "Scientific Entrepreneur". The cluster B includes a few faculties, most of them from Warsaw University of Technology. We can easily recognize that their total number of publications per one student (mean value of the group 0.7) is higher than average in the sample (0.3) and, than in the other clusters. Thus members of the cluster B are definitely stronger in 'theoretical' scientific work than in teaching. The faculties in cluster $\mathrm{C}$ we named "Middlers". They have about 0.24 publications per one student and about 2.6 thous. PLN obtained from externally granted research projects per one student on average. Finally in cluster D we can find faculties strong rather in teaching than in scientific work ('Teachers'). 


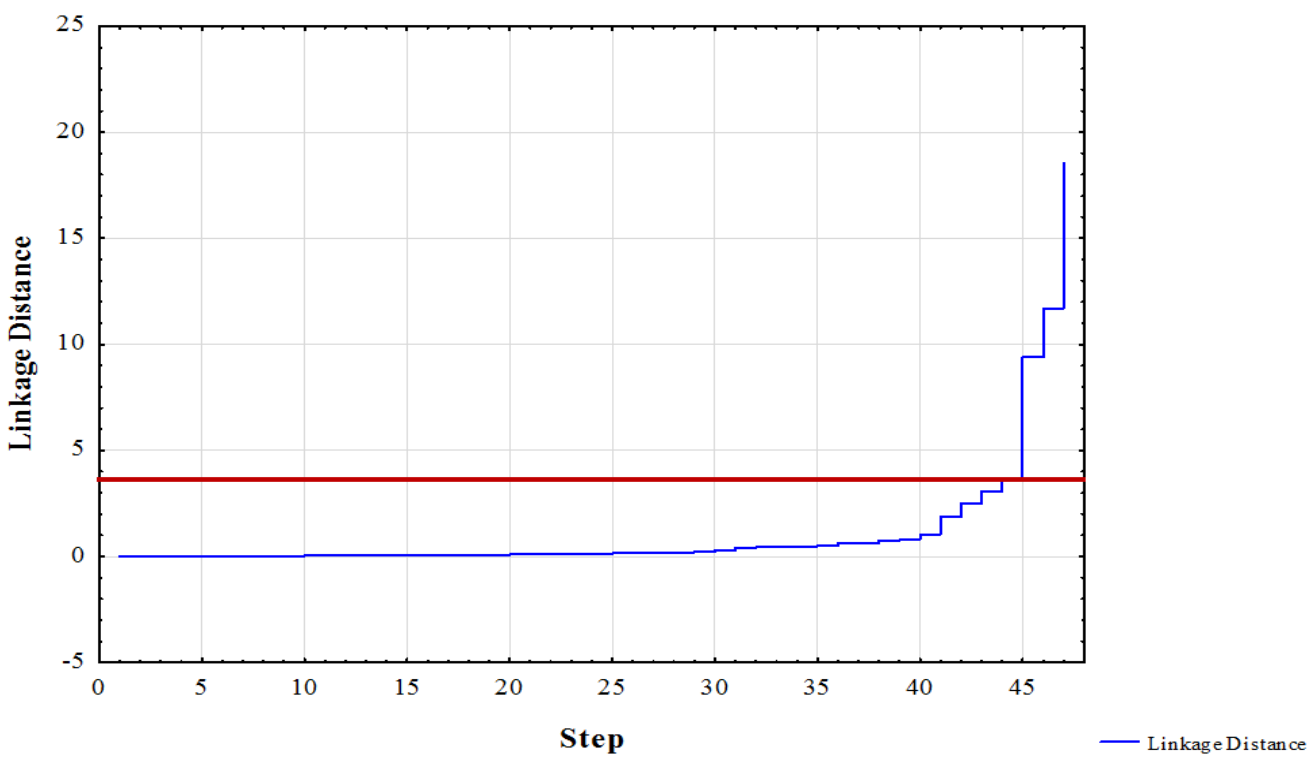

Figure 1. Graph of amalgamation schedule

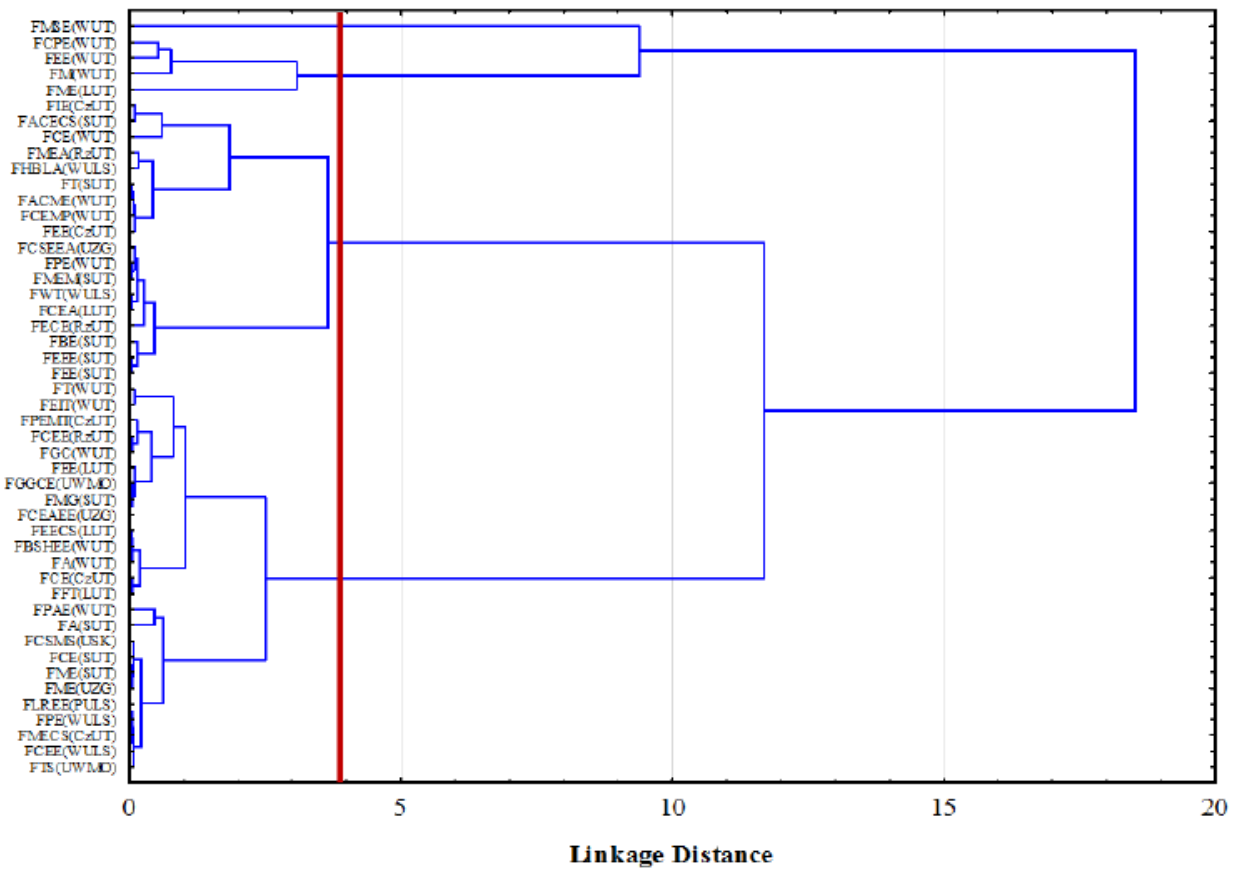

Figure 2. Tree diagram 
Table 1. Characteristics of Clusters

\begin{tabular}{|c|c|c|c|}
\hline $\begin{array}{l}\text { Cluster (total } \\
\text { number of students) }\end{array}$ & ID* & $\begin{array}{l}\text { Number of publications vs } \\
\text { number of students }\end{array}$ & $\begin{array}{l}\text { Value of externally acquired funds } \\
\text { (thous. PLN) vs number of students }\end{array}$ \\
\hline $\begin{array}{l}\text { "Scientific } \\
\text { Entrepreneur" (426) }\end{array}$ & FMSE(WUT) & 0,42 & 93,3 \\
\hline \multirow{4}{*}{ "Authors" (2389) } & FCPE(WUT) & 0,52 & 10,7 \\
\hline & FM(WUT) & 0,61 & 16,3 \\
\hline & FME(LUT) & 0,97 & 4,3 \\
\hline & FEE(WUT) & 0,60 & 6,0 \\
\hline \multirow{18}{*}{$\begin{array}{l}\text { „Middlers” } \\
(31242)\end{array}$} & FIE(CzUT) & 0,34 & 10,1 \\
\hline & FT(WUT) & 0,11 & 4,8 \\
\hline & FACECS(SUT) & 0,35 & 9,3 \\
\hline & FMEA(RzUT) & 0,28 & 4,7 \\
\hline & FCSEEA(UZG) & 0,20 & 1,8 \\
\hline & FHBLA(WULS) & 0,30 & 2,6 \\
\hline & FBE(SUT) & 0,18 & 2,0 \\
\hline & FCE(WUT) & 0,38 & 3,7 \\
\hline & FECE(RzUT) & 0,24 & 1,7 \\
\hline & FWT(WULS) & 0,20 & 0,7 \\
\hline & FPE(WUT) & 0,21 & 0,8 \\
\hline & FMEM(SUT) & 0,21 & 1,0 \\
\hline & FACME(WUT) & 0,28 & 1,0 \\
\hline & FEE(CzUT) & 0,27 & 0,6 \\
\hline & FEEE(SUT) & 0,17 & 0,4 \\
\hline & FCEA(LUT) & 0,20 & 0,3 \\
\hline & FEE(SUT) & 0,18 & 0,2 \\
\hline & FCEMP(WUT) & 0,28 & 0,2 \\
\hline \multirow{4}{*}{$\begin{array}{l}\text { Cluster D - } \\
\text { „Teachers" } \\
(50695)\end{array}$} & FPAE(WUT) & 0,05 & 5,3 \\
\hline & FEIT(WUT) & 0,12 & 5,1 \\
\hline & FPEMT(CzUT) & 0,11 & 2,2 \\
\hline & FCEE(RzUT) & 0,12 & 1,0 \\
\hline
\end{tabular}


Table 1. Characteristics of Clusters (Cont.)

\begin{tabular}{|c|c|c|c|}
\hline $\begin{array}{l}\text { Cluster (total } \\
\text { number of students) }\end{array}$ & ID* & $\begin{array}{l}\text { Number of publications vs } \\
\text { number of students }\end{array}$ & $\begin{array}{l}\text { Value of externally acquired funds } \\
\text { (thous. PLN) vs number of students }\end{array}$ \\
\hline \multirow{21}{*}{$\begin{array}{l}\text { Cluster D - } \\
\text { „Teachers" } \\
(50695)\end{array}$} & FEECS(LUT) & 0,13 & 0,5 \\
\hline & FEE(LUT) & 0,09 & 1,0 \\
\hline & FT(SUT) & 0,28 & 1,3 \\
\hline & FCSMS(USK) & 0,05 & 0,5 \\
\hline & FLREE(PULS) & 0,07 & 0,8 \\
\hline & FMECS(CzUT) & 0,06 & 0,5 \\
\hline & FPE(WULS) & 0,07 & 0,6 \\
\hline & FBSHEE(WUT) & 0,13 & 0,2 \\
\hline & FGC(WUT) & 0,11 & 0,5 \\
\hline & FTS(UWMO) & 0,07 & 0,5 \\
\hline & FCEE(WULS) & 0,06 & 0,3 \\
\hline & FCE(SUT) & 0,06 & 0,3 \\
\hline & FME(SUT) & 0,06 & 0,1 \\
\hline & FGGCE(UWMO) & 0,08 & 0,1 \\
\hline & FMG(SUT) & 0,09 & 0,1 \\
\hline & FA(SUT) & 0,01 & 0,1 \\
\hline & FA(WUT) & 0,14 & 0,0 \\
\hline & FCE(CzUT) & 0,16 & 0,0 \\
\hline & $\begin{array}{l}\text { FFT(LUT) } \\
\text { (L) }\end{array}$ & 0,15 & 0,0 \\
\hline & FCEAEE(UZG) & 0,09 & 0,0 \\
\hline & FME(UZG) & 0,05 & 0,0 \\
\hline
\end{tabular}

* FMSE(WUT) - Faculty of Materials Science and Engineering (Warsaw University of Technology), FCPE(WUT) - Faculty of Chemical and Process Engineering (Warsaw University of Technology), FM(WUT) - Faculty of Mechatronics (Warsaw University of Technology), FME(LUT) - Faculty of Mechanical Engineering (Lublin University of Technology), FEE(WUT) Faculty of Electrical Engineering (Warsaw University of Technology), FIE(CzUT) - Faculty of Infrastructure and Environment (Czestochowa University of Technology), FT(WUT) - Faculty of Transport (Warsaw University of Technology), FACECS(SUT) - Faculty of Automatic Control, Electronics and Computer Science (Silesian University of Technology), FMEA(RzUT) - Faculty of Mechanical Engineering and Aeronautics (Rzeszow University of Technology), FCSEEA(UZG) - Faculty of Computer Science, Electrical Engineering and Automatics (University of Zielona Góra), FHBLA(WULS) - Faculty of Horticulture, Biotechnology and Landscape Architecture (Warsaw University of Life Sciences), FBE(SUT) - Faculty of Biomedical Engineering (Silesian University of Technology), FCE(WUT) - Faculty of Civil Engineering (Warsaw University of Technology), FECE(RzUT) - Faculty of Electrical and Computer Engineering (Rzeszow University of Technology), FWT(WULS) - Faculty of Wood Technology (Warsaw University of Life Sciences), FPE(WUT) - Faculty of Production Engineering ((Warsaw University of Technology), FMEM(SUT) - Faculty of Materials Engineering and Metallurgy (Silesian University of Technology), FACME(WUT) - Faculty of Automotive and Construction Machinery Engineering (Warsaw University of Technology), FEE(CzUT) - Faculty of Electrical Engineering (Czestochowa University of Technology), FEEE(SUT) - Faculty of Energy and Environmental Engineering (Silesian University of Technology), FCEA(LUT) - Faculty of Civil Engineering and Architecture (Lublin University of Technology), FEE(SUT) - Faculty of Electrical Engineering (Silesian University of Technology), FCEMP(WUT) - Faculty of Civil Engineering, Mechanics and Petrochemistry (Warsaw University of 
Technology), FPAE(WUT) - Faculty of Power and Aeronautical Engineering (Warsaw University of Technology), FEIT(WUT) Faculty of Electronics and Information Technology (Warsaw University of Technology), FPEMT(CzUT) - Faculty of Production Engineering and Materials Technology Czestochowa University of Technology), FCEE(RzUT) - Faculty of Civil and Environmental Engineering (Rzeszow University of Technology), FEECS(LUT) - Faculty of Electrical Engineering and Computer Science (Lublin University of Technology), FEE(LUT) - Faculty of Environmental Engineering (Lublin University of Technology), FT(SUT) - Faculty of Transport (Silesian University of Technology), FCSMS(USK) - Faculty of Computer Science and Materials Science (University of Silesia in Katowice), FLREE(PULS) - Faculty of Land Reclamation and Environmental Engineering (Poznan University of Life Sciences), FMECS(CzUT) - Faculty of Mechanical Engineering and Computer Science (Czestochowa University of Technology), FPE(WULS) - Faculty of Production Engineering (Warsaw University of Life Sciences), FBSHEE(WUT) - Faculty of Horticulture, Biotechnology and Landscape Architecture (Warsaw University of Life Sciences), FGC(WUT) - Faculty of Geodesy and Cartography (Warsaw University of Technology), FTS(UWMO) - Faculty of Technical Sciences (University of Warmia and Mazury in Olsztyn), FCEE(WULS) - Faculty of Civil and Environmental Engineering (Warsaw University of Life Sciences), FCE(SUT) - Faculty of Civil Engineering (Silesian University of Technology), FME(SUT) - Faculty of Mechanical Engineering (Silesian University of Technology), FGGCE(UWMO) - Faculty of Geodesy, Geospatial and Civil Engineering (University of Warmia and Mazury in Olsztyn), FMG(SUT) - Faculty of Mining of Geology (Silesian University of Technology), FA(SUT) - Faculty of Architecture (Silesian University of Technology), FA(WUT) - Faculty of Architecture (Warsaw University of Technology), FCE(CzUT) - Faculty of Civil Engineering (Czestochowa University of Technology), FFT(LUT) - Faculty of Fundamentals of Technology (Lublin University of Technology), FCEAEE(UZG) - Faculty of Civil Engineering, Architecture and Environmental Engineering (University of Zielona Góra), FME(UZG) - Faculty of Mechanical Engineering (University of Zielona Góra).

We visualize results of clustering in the form of the strategic groups map (figure 3), which is a graphic illustration of the strategic diversity of faculties of engineering and technology sciences in Poland. The map shows which group is strong in teaching, which in 'theoretical work' and which in 'practical' research (entrepreneurial behaviour).

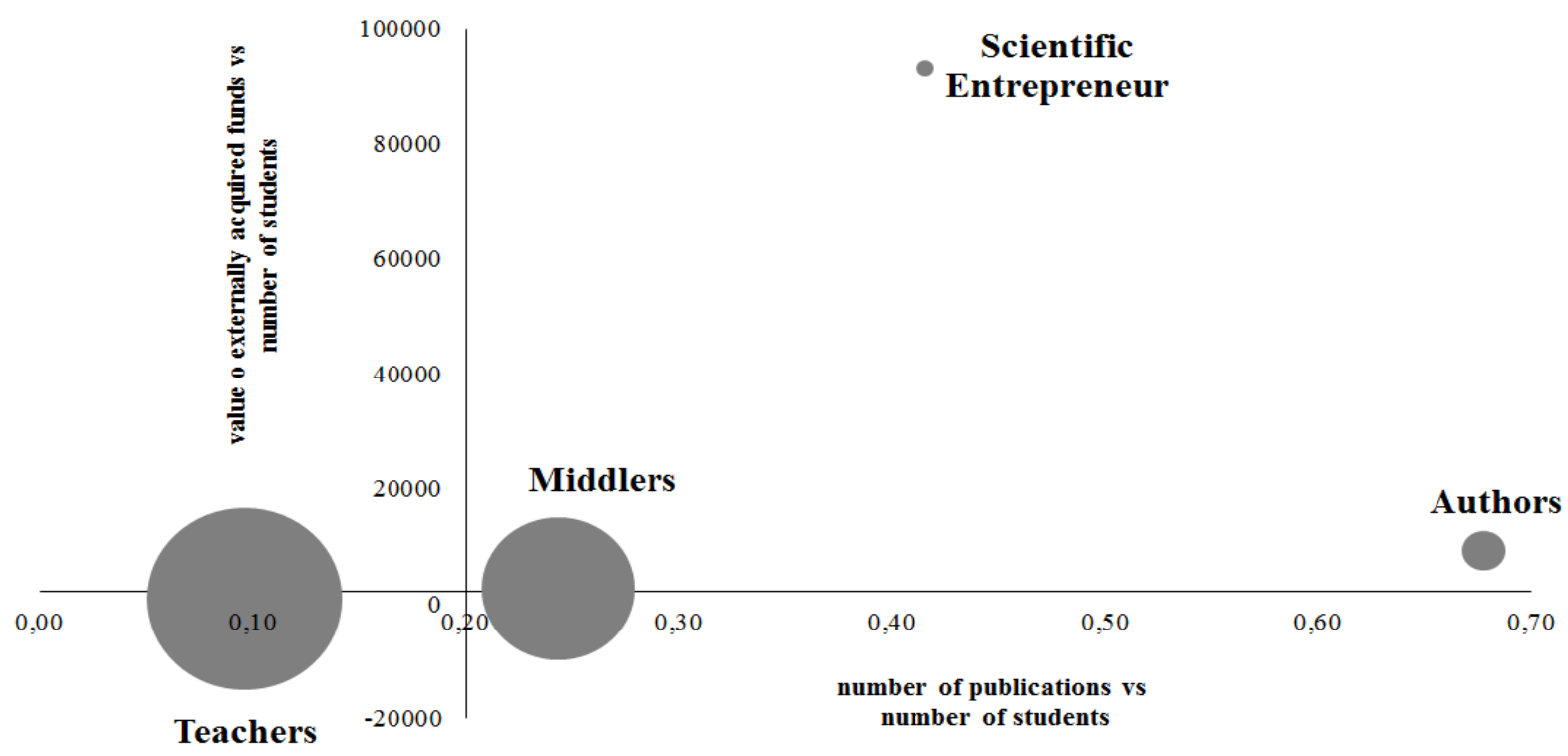

Figure 3. Strategic groups

In the next step of analysis we compared strategic groups' membership with their efficiency (DEA scores). Based on DEA efficiency scores, faculties were divided into three groups: highefficient (above the $66^{\text {th }}$ percentile), medium-efficient (above the $33^{\text {rd }}$ percentile and under the $66^{\text {th }}$ percentile) and inefficient (under the $33^{\text {rd }}$ percentile). The results of a survey are tabulated below (see table 2). Based on chi-square $\left(\chi^{2}\right)$ statistics, we find that efficiency is related to strategic groups' membership. Note that, for instance, that in most cases "Middlers" were 
inefficient (61\% of them, see table 2), whilst in the case of "Authors" every one out of two of them is high-efficient. "Scientific Entrepreneur" is high-efficient. 40\% of "Teachers" are high efficient.

Table 2. Contingency Table for Clusters

\begin{tabular}{|l|l|l|l|l|}
\hline Cluster & High-efficient & Medium-efficient & Inefficient & Totals \\
\hline Scientific Entrepreneur & $1(100 \%)$ & $0(0 \%)$ & $0(0 \%)$ & $1(2 \%)$ \\
\hline Authors & $2(50 \%)$ & $1(25 \%)$ & $1(25 \%)$ & $4(8 \%)$ \\
\hline Middlers & $3(17 \%)$ & $4(22 \%)$ & $11(61 \%)$ & $18(38 \%)$ \\
\hline Teachers & $10(40 \%)$ & $10(40 \%)$ & $5(20 \%)$ & $25(52 \%)$ \\
\hline Totals & $16(33 \%)$ & $15(31 \%)$ & $17(36 \%)$ & $48(100 \%)$ \\
\hline
\end{tabular}

\section{Conclusions}

This paper is an attempt to establish strategic groups maps for the sector of faculties of engineering and technology sciences in Poland. Basing on two dimensions: the number of publications versus the number of students (which illustrates the tension between 'theoretical' research and teaching) and the value of externally acquired funds versus the number of students (which illustrates the tension between 'practical' research activity and teaching) we clustered 48 faculties from the sample into four strategic groups: "Scientific Entrepreneur" focused on 'practical' research, "Authors" focused on 'practical' research, "Teachers" focused on teaching and "Middlers" without clear positioning.

We find that there exist the relationship between strategic groups' membership and performance measured by DEA efficiency score (on the 0.05 level of significance). Generally speaking, one could find, that the performance is correlated with the clear strategic specialization. The worst results were obtained by: "Middlers" - this is in line with the concept of "stuck-in-the-middle" trap described by Porter (1998a).

One could find surprising about the quite well results of "Teachers" because it is a little bit against an academic snobbery. Such situation could be interpreted as confirmation of the postulated in strategic literature need of clear positioning (e.g. Porter, 1998a). However, on the other hand the environment of the public universities in Poland is not like a free and competitive market. Indeed, the government substantially regulates it. Up till now regulation was such that it was financially rewarding for faculty to have more and more students at public university. However, most recently regulation is changing. The incentives are constructed in that way, that it will be prohibitively unprofitable when the ratio of students per academic staff will exceed 13. It will be interesting to repeat our research under the new regulation to verify if still "Teachers" will be efficient. One could predict the strategic move (escape) from this group to the others. However one could also expect relatively high mobility barriers protecting "Scientific Entrepreneur" and "Authors" and law mobility barriers around "Middlers". Thus the move from "Teachers" into "Middlers" could be most easy and therefore most probable.

However, one should be aware about limitations of our study. Firstly, it is very difficult to select the criteria of differentiation strategy in the sector of higher education. In this aspect we followed 
general idea of Warning (2004), that there is strategic trade-off between teaching and research. Secondly, it is also very difficult to measure performance of universities and faculties. DEA method is not a panacea. Moreover, the available data set is very limited and allows only for construction of only simple measures. Thirdly, only 48 out of the 150 faculties of engineering and technology sciences functioning in Poland were investigated. Thus, the results of the analysis are incomplete. The sample was not randomized and should be treated only as a pilot study. Therefore, further investigations are needed. We suggest following our approach to investigate the competitive situation in the sector of higher education at faculty rather than at the university level.

\section{References}

Adam, A. K. (2016). Strategy and success factors of business schools. Wiesbaden, Germany: Springer Gabler.

Ansoff, H. I. (1979). Strategic management. London and Basingstoke: Macmilan Press.

Begg, D., Fischer, S., \& Dornbusch R. (2014). Economics 9th edition. London and United States: McGraw-Hill.

Bonaccorsi, A. (2014). Knowledge, diversity and performance in European higher education. A Changing Landscape, Cheltenham-Northampton: Edward Elgar.

Bowden, E. V., \& Bowden, J. H. (2001). Economics: The science of the common sense. Cary, NC: OpenMind.

Carlton, D., \& Perloff, J. M. (2005). Modern industrial organization. New York, NY: Pearson Addison Wesley.

Charnes, A., Cooper, W. W., \& Rhodes, A. (1978). Measuring the efficiency of decision making units. European Journal of Operational Research, 2(6), 429-444.

De Wit, B., \& Meyer, R. (2010). Strategy synthesis: Resolving strategy paradoxes to create competitive advantage. London, UK: Thomson Learning.

Domański, J. (2010). Strategic group analysis of Poland's nonprofit organizations. Nonprofit and Voluntary Sector Quarterly, 39(6), 1113-1124.

Fiegenbaum, A., McGee, J., \& Thomas, H. (1987). Exploring the linkage between strategic groups and competitive strategy. International Studies of Management and Organization, $18(1), 6-25$.

Hair, J. F, Black, W. C., Babin B. J., \& Anderson, R. E. (2009). Multivariate data analysis: A global perspective. London, UK: Pearson Publications.

Hatten, K. J., \& Hatten, M. L. (1987). Strategic groups, asymmetrical mobility barriers and contestability. Strategic Management Journal, 8(4), 329-342.

Hood, C. (1991). A public management for all seasons? Public Administration, 69(1), 3-19.

Martinez, M., \& Wolverton, M. (2009). Innovative strategy making in higher education. Charlotte, NC: Information Age Publishing. 
McGahan, A. M., \& Porter, M. E. (1997). How much does industry matter, really? Strategic Management Journal, 18, 15-30.

McGee, J., \& Thomas, H. (1986). Strategic groups: Theory, research and taxonomy. Strategic Management Journal 7(2), 141-160.

McMahon, W. W. (1982). Externalities in education. Faculty Working Paper, 877.

Mintzberg H., Ahlstrand B., \& Lampel J. (1998). Strategy safari: A guided tour through the wilds of strategic management. New York, NY: Free Press.

Nath, D., \& Gruca, T. S. (1997). Convergence across alternative methods for forming strategic groups. Strategic Management Journal, 18(9), 745-760.

O’Flynn, J. (2007). From new public management to public value: Paradigmatic change and managerial implications. The Australian Journal of Public Administration, 66(3), 353366.

Parker, L. D. (2012). From privatised to hybrid corporatised higher education: A global financial management discourse. Financial Accountability \& Management, 28(3), 247-268.

Pietrzak, M. (2014). Using the strategy map as a strategic communication tool in higher education: A case study of Warsaw University of Life Sciences. Online Journal of Applied Knowledge Management, 2(2), 26-42.

Pietrzak, M., Paliszkiewicz, J., \& Klepacki, B. (2015a). The application of the balanced scorecard (BSC) in the higher education setting of a Polish university. Online Journal of Applied Knowledge Management, 3(1), 151-164.

Pietrzak M., Jałosiński K., Paliszkiewicz J., \& Brzozowski, A. (2015b). A case study of strategic group map application used as a tool for knowledge management. Journal of Computer Information Systems, 55(2), 68-77.

Porter, M. E. (1981). The contributions of industrial organization to strategic management. The Academy of Management Review, 6(4), 609-620.

Porter, M. E. (1990). The competitive advantage of nations. New York, NY: Free Press.

Porter M. E. (1998a). Competitive strategy: Techniques for analyzing industries and competitors, New York, NY: Free Press.

Porter, M. E. (1998b). Competitive advantage: Creating and sustaining superior performance. New York, NY: The Free Press.

Pruett, M., \& Thomas, H. (1994). Introduction [in:] Daems, H., Thomas, H. (ed.) Strategic groups, strategic moves and performance. Great Yarmouth, Pergamon, vii-xii.

Rumelt, R. P. (1991). How much does industry matter? Strategic Management Journal, 12(3), 167-185.

Rumelt, R. P., Schendel, D., \& Teece, D. J. (1991). Strategic management and economics. Strategic Management Journal, 12, 5-29. 
Schimank, U. (2005). 'New public management' and the academic profession: Reflections on the German situation. Minerva, 43(4), 361-376.

Schmalensee, R. (1985). Do markets differ much? The American Economic Review, 75(3), 1985, 41-351.

Tahar, S. (2013). Resource allocation in higher education in the context of new public management. Public Management Review, 15(5), 687-711.

Thompson, A. A., \& Strickland A. J. (1990). Strategic management: Concepts and cases. Homewood, IL: Richard D. Irwin.

Thompson, A. A., Peteraf M. A., Gamble J. E., \& Strickland A. J. (2012). Crafting and executing strategy: Concepts and cases. IL: McGraw Hill.

Warning, S. (2004). Performance differences in German higher education: Empirical analysis of strategic groups. Review of Industrial Organization, 24(4), 393-408.

Warning, S. (2007). The economic analysis of universities: Strategic groups and positioning, Cheltenham, UK: Edward Elgar.

Wilkesman, U., \& Schmid, C. J. (2012). The impacts of new governance on teaching at Germany universities. Findings from a national survey. Higher Education, 63(1), 33-52.

Wójcik-Augustyniak, M. (2011). Analysis of the strategic groups maps of the higher schools sector in Poland. Zeszyty Naukowe Uniwersytetu Przyrodniczo-Humanistycznego w Siedlcach. Seria: Administracja i Zarzadzanie, 91(18), 115-127.

\section{Authors' Biographies}

Michal Pietrzak is a strategic management and performance measurement researcher and practitioner. He is a professor at Faculty of Economic Sciences at Warsaw University of Life Sciences - SGGW and a vice chairman of the committee responsible for the strategy of this university. His main areas of interest include industrial organization and competitive strategy, Balanced Scorecard, performance measurement, and strategic learning. His consultancy experience covers strategic analyses, strategy development, BSC implementation for automotive, energy, chemistry, professional services, municipal services, public agencies and universities.

Piotr Pietrzak is a performance measurement researcher. He is an assistant professor at Faculty of Economic Sciences at Warsaw University of Life Sciences - SGGW. His main areas of interest include efficiency of public sector institutions, performance measurement, Balanced Scorecard. 